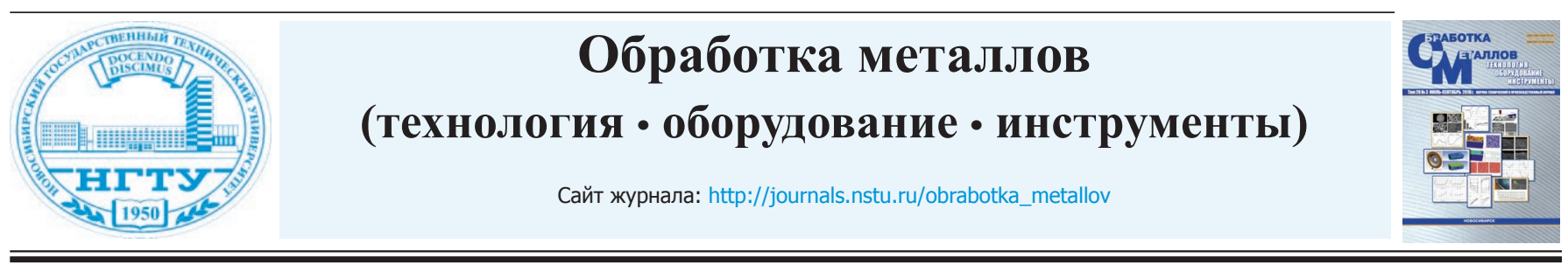

Повышение эффективности упрочнения поверхностей ферромагнитных деталей совмещенным магнитно-динамическим накатыванием

\author{
Александр Довгалев*
}

Белорусско-Российский университет, пр. Мира, 43, г. Могилёв, 212030, Республика Беларусь

(D) https://orcid.org/0000-0001-5946-5134, @ rct@bru.by

ИНФОРМАЦИЯ О СТАТЬЕ

УДК 621.787

История статьи:

Поступила: 15 декабря 2017

Рецензирование: 10 января 2018

Принята к печати: 21 июня 2018

Доступно онлайн: 15 сентября 2018

Ключевые слова:

Магнитно-динамическое

накатывание

Поверхностное пластическое

деформирование

Магнитная система

Совмещенная обработка

Деформирующие шары

Импульсно-ударное

деформирование

Магнитное поле

Наноразмерная субзеренная

структура

\section{АННОТАЦИЯ}

Введение. Эксплуатационные свойства поверхностей деталей технических систем обеспечиваются на финишных операциях технологического процесса методами поверхностного упрочнения. Несмотря на существующее достаточно большое количество методов поверхностной упрочняющей обработки, многие из них имеют узкую область технологического применения и для своей реализации требуют специального дорогостоящего оборудования, другие не доведены до стадии широкого практического применения или исчерпали свои технологические возможности. В связи с этим разработка инновационных методов отделочно-упрочняющей обработки поверхностей деталей машин является актуальной задачей. Цель работы - повышение эффективности упрочнения на основе комплексного энергетического воздействия на поверхностный слой ферромагнитных деталей вращающимся магнитным полем и динамическим поверхностным пластическим деформированием. Гипотеза исследования - совмещенное магнитно-силовое воздействие на поверхность ферромагнитной детали способствует измельчению зерен деформируемого металла до наноразмерной величины и обеспечивает увеличение глубины модифицированного (измененного) поверхностного слоя. В работе представлен метод отделочно-упрочняющей обработки, при котором на поверхность ферромагнитной детали одновременно воздействуют концентрированным потоком энергии вращающегося магнитного поля и колеблющимися деформирующими шарами, осуществляющими многократное импульсно-ударное деформирование. При этом индукцию вращающегося магнитного поля, действующего на поверхность детали, выбирают в пределах от 0,10 до 1,20 Тл. Для осуществления метода отделочно-упрочняющей обработки разработан комбинированный инструмент, содержащий: корпус; деформирующие шары, свободно установленные в кольцевой камере; магнитную систему на основе цилиндрических постоянных магнитов из редкоземельных материалов. Магнитная система инструмента предназначена для создания вращающегося магнитного поля, действующего на поверхность ферромагнитной детали и сообщения деформирующим шарам рабочих колебательных движений. В работе исследованы характеристики дислокационных структур, образованных в поверхностном слое стальных и чугунных заготовок после упрочнения магнитно-динамическим накатыванием (МДН), совмещенной обработкой МДН и вращающимся постоянным магнитным полем, совмещенной обработкой МДН и вращающимся переменным магнитным полем. Методы исследования: рентгеноструктурные исследования поверхностного слоя; исследования микроструктуры; рентгеноспектральный микроанализ поверхностного слоя упрочненных заготовок из стали и чугуна. Результаты и обсуждение. Анализ результатов исследований позволил установить, что совмещенная упрочняющая обработка МДН и вращающимся магнитным полем позволяет сформировать в поверхностном слое стальных и чугунных заготовок наноразмерную субзеренную структуру на глубину до 3,0 мкм с размером блоков до 100 нм. При этом имеет место увеличение глубины модифицированного поверхностного слоя, плотности дислокаций, периода кристаллической решетки обрабатываемых ферромагнитных материалов и формирование в упрочненном поверхностном слое образцов остаточных напряжений сжатия. Из представленной в работе физической модели получения в поверхностном слое ферромагнитных деталей наноразмерной субзереной структуры следует, что степень дробления (измельчения) зерен упрочняемого материала определяется количеством полученных силовых импульсов со стороны деформирующих шаров инструмента. Возникающие в процессе многократного дробления зерен и субзерен частицы имеют неправильную асимметричную форму и свой магнитный момент, не совпадающий с направлением действия внешнего магнитного поля. Вследствие этого полученные в процессе дробления зерен и субзерен частицы, стремящиеся сориентироваться по направлению внешнего магнитного поля, поворачиваются в пространстве и дополнительно сглаживают разогретые локальными вихревыми токами границы в зоне их контакта с сопрягаемыми фрагментами частиц, характеризующимися накоплением несовершенств в виде дислокаций. Разработанный метод совмещенного МдН относится к нанотехнологиям поверхностной модификации и рекомендуется к внедрению на предприятиях машиностроения для повышения эксплуатационных свойств деталей технических систем. 
Для цитирования: Довгалев А.M. Повышение эффективности упрочнения поверхностей ферромагнитных деталей совмещенным магнитно-динамическим накатыванием // Обработка металлов (технология, оборудование, инструменты). - 2018. - Т. 20, № 3. C. 18-35. - doi: 10.17212/1994-6309-2018-20.3-18-35.

\footnotetext{
*Адрес для переписки

Довгалев Александр Михайлович, к.т.н., доцент

Белорусско-Российский университет,

пр. Мира, 43,

212030 , г. Могилёв, Республика Беларусь

Тел.: +375222 2536 03, e-mail: rct@bru.by
}

\section{Введение}

Большинство выходов из строя современных машин и механизмов связано с износом поверхностей входящих в них ответственных деталей. Анализ напряженно-деформированного состояния деталей машин показывает, что основную эксплуатационную нагрузку воспринимает их поверхностный слой. В связи с этим эксплуатационные свойства, в том числе износостойкость деталей, зависят от качественных характеристик их поверхностного слоя. Это определяет актуальность разработки и применения новых эффективных технологий поверхностного упрочнения деталей, обеспечивающих повышение надежности и долговечности технических систем [1-3].

В настоящее время создано достаточно большое количество методов поверхностного упрочнения деталей машин, каждый из которых имеет свои особенности, определяющие область его технологического применения. К их числу относятся методы упрочнения поверхностей деталей концентрированным потоком энергии (ионно-плазменное упрочнение, электронно-лучевая обработка, ионно-диффузионное насыщение, плазменное напыление покрытий и др.), термической и химикотермической обработкой (поверхностная индукционная и лазерная закалка, ионное азотированое, борирование, силицирование), магнитным полем (постоянным, переменным, импульсным) и др. [4-15].

Многие из указанных методов поверхностной упрочняющей обработки имеют свою узкую область применения и для своей реализации требуют специального дорогостоящего оборудования, другие не доведены до стадии широкого практического применения или исчерпали свои технологические возможности.

В связи с этим предпочтительными являются динамические методы поверхностного пласти- ческого деформирования (ППД), применяемые для обработки как мелких, так и крупногабаритных деталей, являющихся универсальными и экологически безопасными, позволяющие обеспечить упрочнение поверхностного слоя, получить микрорельеф с низкой шероховатостью, сформировать благоприятные остаточные напряжения, повысить усталостную прочность, контактную выносливость и износостойкость упрочняемых поверхностей [16-18]. Однако и у динамических методов ППД (обработка дробью, вибронакатывание, ультразвуковая, центробежно-ударная, пневмоцентробежная, пневмовибродинамическая и другие), используемых для упрочнения поверхностного слоя деталей (включая нежесткие), существуют недостатки, связанные с применением достаточно сложных технологических систем, они имеют относительно низкую производительность, не предусматривают комплексного энергетического воздействия на поверхностный слой упрочняемой детали, позволяющего обеспечить формирование наноструктурированной упрочненной поверхности с высокими трибологическими свойствами.

В связи с этим актуальной является разработка инновационных методов ППД, позволяющих обеспечивать комплексное энергетическое воздействие на поверхностный слой детали, повышающее эффективность процесса упрочнения.

В соответствии с поставленной задачей разработан метод совмещенной упрочняющей обработки поверхностей ферромагнитных деталей концентрированным потоком энергии вращающегося магнитного поля и колеблющимися деформирующими шарами, осуществляющими многократное импульсно-ударное деформирование (далее метод совмещенного магнитно-динамического накатывания). Величину индукции магнитного поля, действующего на поверхность ферромагнитной детали, следует выбирать в пределах от 0,10 до 1,20 Тл [19-21].

Гипотеза исследований - комплексное магнитно-силовое воздействие на поверхностный слой ферромагнитной детали способствует измельчению зерен деформируемого металла до наноразмерной величины и обеспечивает увели- 
чение глубины модифицированного (измененного) поверхностного слоя.

Для реализации метода совмещенного магнитно-динамического накатывания (МДН) спроектирован комбинированный инструмент, изображенный на рис. 1.

В состав инструмента входят следующие элементы: оправка 1 ; шайбы 2, 3; кольцевая камера 4; деформирующие шары 5 ; две независимые магнитные системы. Магнитная система, обеспечивающая воздействие на поверхностный слой ферромагнитной детали вращающимся магнитным полем, включает: диски 6, 7 с аксиальными отверстиями 8,9 ; цилиндрические постоянные магниты 10, 11 и магнитоприводы 12 , 13. Магнитная система, предназначенная для сообщения деформирующим шарам 5 интенсивных колебательных движений, осуществляющих многократное импульсно-ударное деформирование, содержит: обоймы 14,15 с аксиальными отверстиями 16,17 ; цилиндрические постоянные магниты 18, 19; магнитопроводный диск 20 с пе-

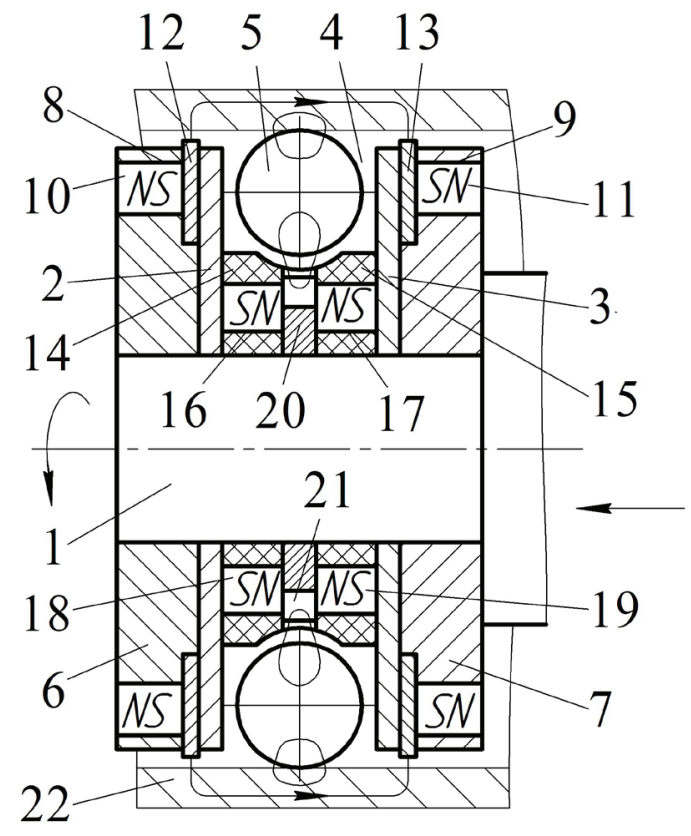

Puc. 1. Комбинированный инструмент для совмещенной упрочняющей обработки внутренней цилиндрической поверхности ферромагнитных тел вращения МДН и вращающимся постоянным или переменным магнитным полем

Fig. 1. A combined tool for combined strengthening treatment of the inner surface of rotating bodies by magnetic-dynamic rolling and a rotating constant or alternating magnetic field. риодической поверхностью 21 в виде синусоиды или выступов. Оправка 1 , шайбы 2,3 , диски 6,7 , обоймы 14 и 15 изготовлены из немагнитопроводных материалов.

Оправку 1 инструмента устанавливают в шпинделе, а упрочняемую ферромагнитную втулку 22 закрепляют соосно в технологическом приспособлении станка. Инструмент вводят в цилиндрическое отверстие втулки 22 с зазором между упрочняемой поверхностью и наружной поверхностью магнитопроводов 12, 13. Магнитный поток от цилиндрических постоянных магнитов 10, 11 при этом замыкается на внутреннюю поверхность втулки 22. Инструменту сообщают вращение и перемещают с осевой подачей. Вращаясь вместе с оправкой 1 , цилиндрические постоянные магниты 18,19 посредством магнитопроводного диска 20 с поверхностью 21 в виде зубьев периодически воздействуют магнитным полем на деформирующие шары 5 и перемещают их в окружном направлении кольцевой камеры 4. При этом угловая скорость вращения цилиндрических постоянных магнитов 18, 19 превышает угловую скорость вращения деформирующих шаров 5. Вследствие этого на деформирующие шары (одновременно с центробежной силой) действует радиально-направленная периодическая магнитная сила, отрывающая их от упрочняемой поверхности. В результате деформирующие шары 5 получают радиальные колебательные движения, вследствие которых и осуществляется многократное импульсно-ударное деформирование поверхности детали 22. Одновременно внутренний поверхностный слой втулки 22 упрочняется вращающимся магнитным полем, создаваемым цилиндрическими постоянными магнитами 10, 11 .

Разработанный инструмент в зависимости от последовательности расположения полюсов $\mathrm{N}$ и $\mathrm{S}$ цилиндрических постоянных магнитов 10, 11 (одновременно с многократным импульсно-ударным деформированием) обеспечивает воздействие на поверхность ферромагнитной детали вращающимся постоянным или переменным (изменяющим направление силовых линий на $180^{\circ}$ ) магнитным полем. Так, при установке цилиндрических постоянных магнитов 10, 11 в аксиальных отверстиях 8,9 дисков 6,7 с одинаковым расположением полюсов инструмент обеспечивает воздействие на поверхность ферро- 
магнитной детали вращающимся постоянным, а при последовательном чередовании полюсов указанных магнитов - переменным магнитным полем.

Таким образом, в процессе совмещенной обработки деформируемый участок поверхности ферромагнитной детали испытывает комплексное магнитно-силовое воздействие, повышающее эффективность процесса упрочнения [22].

Целью работы является повышение эффективности упрочнения на основе комплексного энергетического воздействия на поверхностный слой ферромагнитных деталей вращающимся магнитным полем и динамическим поверхностным пластическим деформированием.

\section{Методика экспериментального исследования}

Для определения эффективности процесса совмещенного МДН, подтверждения гипотезы исследований и оценки роли действующего на обрабатываемый материал вращающегося магнитного поля использовали заготовки в виде колец с размерами $(D \times d \times h)-130 \times 110 \times 12$ мм из стали 45 (30-35 HRC) и серого чугуна СЧ 20 (145...155 НВ). Кольца из стали 45 предварительно проходили термическую обработку (закалка + отпуск) с обеспечением следующих режимов: $t_{\text {зак }}=860^{\circ} ; T_{\text {зак }}=40$ мин; $t_{\text {отп }}=500^{\circ}$; $T_{\text {отп }}=180$ мин. Кольца из серого чугуна СЧ 20 упрочняли в состоянии поставки.

Отверстия стальных и чугунных колец перед упрочнением растачивали в размер Ø110Н8 $8^{(+0,054)}$ на токарно-винторезном станке $16 Д 25$ (материал режущей части инструмента - Т15К6, глубина резания $t=0,25 \mathrm{мM} ; V=109 \mathrm{м} / \mathrm{мин;} s=0,15 \mathrm{мм} /$ мин). Исходная шероховатость поверхности отверстия колец после чистового растачивания по параметру $R a$ составляла 6,3...6,0 мкм.

Внутренние цилиндрические поверхности указанных ферромагнитных заготовок упрочняли следующими технологическими методами: магнитно-динамическим накатыванием (МДН); совмещенной обработкой МДН и вращающимся постоянным магнитным полем; совмещенной обработкой МДН и вращающимся переменным магнитным полем.

Реализацию методов упрочнения осуществляли на вертикально-фрезерном станке мод.
ВФ-130 с применением инструмента, изображенного на рис. 1. При этом для осуществления процесса МДН в инструменте не устанавливали цилиндрические постоянные магниты 10 , 11. При совмещенной упрочняющей обработке МДН и вращающимся постоянным магнитным полем цилиндрические постоянные магниты 10 , 11 устанавливали в дисках 6,7 с одинаковым расположением полюсов $\mathrm{N}$ и $\mathrm{S}$, а при совмещенной обработке МДН и вращающимся переменным магнитным полем - с последовательным расположением полюсов $\mathrm{N}$ и $\mathrm{S}$.

Применение для реализации указанных методов упрочнения конструкции переналаживаемого инструмента обеспечило корректность сравнения полученных результатов исследований.

Параметры применяемого инструмента: диаметр обрабатываемых отверстий заготовок от 108 до 112 мм; деформирующие шары Ø 12 мм, сталь ШХ15 (62-65 HRC); материал цилиндрических постоянных магнитов - $\mathrm{Nd} \mathrm{Fe} \mathrm{B}$; размер цилиндрических постоянных магнитов $(\mathrm{D} \times l)-$ $15 \times 10$ мм; количество магнитов, осуществляющих воздействие на деформирующие шары, 12 шт.; индукция $(B)$ магнитного поля в зоне расположения деформирующих шаров $-0,15$ Тл; количество цилиндрических постоянных магнитов, осуществляющих намагничивание внутренней поверхности ферромагнитных колец 24 шт.; материал кольцевых магнитопроводов сталь Ст.3.

Режимы упрочняющей обработки: частота (скорость) вращения инструмента $n=3150$ мин $^{-1}$ $(V=18 \mathrm{M} / \mathrm{c})$; осевая подача инструмента $S=$ $=20 \mathrm{Mм} /$ мин; количество рабочих ходов инструмента - один; смазочно-охлаждающая жидкость - масло индустриальное 45; зазор между упрочняемой поверхностью заготовок и кольцевыми магнитопроводами - 0,30 мм; индукция $(B)$ вращающегося магнитного поля, действующего на внутреннюю поверхность ферромагнитных колец при реализации методов совмещенного упрочнения, находилась в пределах 0,095...0,100 Тл; частота перемагничивания поверхностного слоя колец составляла $v=630 \mathrm{c}^{-1}$ (при совмещенном упрочнении МДН и вращающимся переменным магнитным полем).

Для определения характеристик упрочнения образцов были проведены рентгеноструктурные исследования, исследования микроструктуры, а 
также рентгеноспектральный микроанализ поверхностного слоя. Образцы для исследований вырезали из упрочненных колец при обильной подаче охлаждающей жидкости.

Рентгеноструктурные исследования поверхностного слоя упрочненных колец выполняли на автоматизированном рентгеновском комплексе на базе дифрактометра ДРОН-3М в СоК $\alpha-$ и $\mathrm{CuK \alpha -излучениях} \mathrm{с} \mathrm{применением} \mathrm{монохрома-}$ тизации дифрагированного пучка. В качестве кристалла-монохроматора использовали пластину пиролитического графита. Для получения информации о структуре поверхностных слоев проводили запись дифракционных линий (110) и (220) матричной $\alpha$-Fe фазы, расположенных в интервале углов рассеяния $2 \theta=48 \ldots 56^{\circ}, 2 \theta=$ $=118 \ldots 130^{\circ}(\mathrm{CoK} \alpha)$ и $2 \theta=40 \ldots 49^{\circ}, 2 \theta=93 \ldots 103^{\circ}$ $(\mathrm{CuK \alpha})$ соответственно. Рентгеновская съемка выполнялась в режиме сканирования (по точкам) с шагом $0,1^{\circ}$. Продолжительность набора импульсов в точке составляла 20 с.

Период кристаллической решетки материала образцов, а также напряженное состояние в поверхностных слоях оценивали по результатам записи дифракционной линии (220). Физическое уширение $\beta$ исследуемых дифракционных линий находили методом аппроксимации с введением поправок на геометрию съемки и неоднородность излучения. В качестве функции $f(x)$, определяющей распределение интенсивности в линиях эталона и исследуемых образцов, использовали функцию вида $\frac{1}{\left(1+\alpha x^{2}\right)^{2}}$ [23].

Размер $D$ субзерен, сформировавшихся в поверхностном слое упрочненных образцов, находили по соответствующим дифракционным линиям из выражения [24]:

$$
D=\lambda /(\beta \cos \theta),
$$

где $\lambda$ - длина волны рентгеновского излучения; $\theta-$ угол рассеяния.

Согласно [24] физическое уширение дифракционных линий, обусловленное дислокациями, пропорционально $\operatorname{tg} \theta$, а плотность дислокаций, рассчитанная по их уширению, удовлетворительно согласуется с данными прямых методов наблюдения дислокаций. В соответствии с [25] плотность дислокаций $\rho$ определяли из выражения

$$
\rho=m \beta^{2} \operatorname{ctg}^{2} \theta / b^{2},
$$

где $m$ - коэффициент, учитывающий тип дислокаций и кристаллической решетки, $m=1 ; b-$ вектор Бюргерса, $b=1,35 \cdot 10^{-7}$ мм.

Для оценки микроискажений (смещений атомов из своих положений вдоль определенных направлений кристаллической решетки) в деформированном материале выбирали соотношение величин $\Delta a / a\left(\Delta a=a-a_{0}\right.$, где $a, a_{0}-$ периоды решетки соответственно упрочненного и неупрочненного материала заготовок.

Оценку напряжений в поверхностных слоях упрочненных образцов проводили при условии плосконапряженного состояния (нормальная составляющая напряжений принималась равной нулю). В этом случае суммарные тангенциальные напряжения определяли по формуле [7]

$$
\sigma_{1}+\sigma_{2}=\frac{E}{\mu} \frac{\Delta d}{d}
$$

где $E$ - модуль упругости 1 -го рода; $\mu$ - коэффициент Пуассона; $\Delta d / d$ - относительное изменение межплоскостного расстояния для анализируемой линии по отношению к положению соответствующей линии неупрочненного образца.

Анализ микроструктуры поверхностного слоя упрочненных образцов проводили при помощи сканирующего электронного микроскопа высокого разрешения MIRA.

Рентгеноструктурный микроанализ образцов выполняли с использованием микроанализатора EDX INCA 350X - Max.

Подготовку образцов для металлографического анализа осуществляли по стандартной методике.

\section{Результаты и обсуждения}

Результаты рентгеноструктурного анализа упрочненного поверхностного слоя, а именно профили дифракционных линий, значения физического уширения дифракционных линий, размеры блоков субзеренной структуры, значения характеристик упрочнения (плотность дислокации (р), период кристаллической решетки $(a)$, напряжение сжатия и другие) для образцов из стали и серого чугуна представлены соответственно на рис. 2 и 3, а также в табл. 1-4. 
110
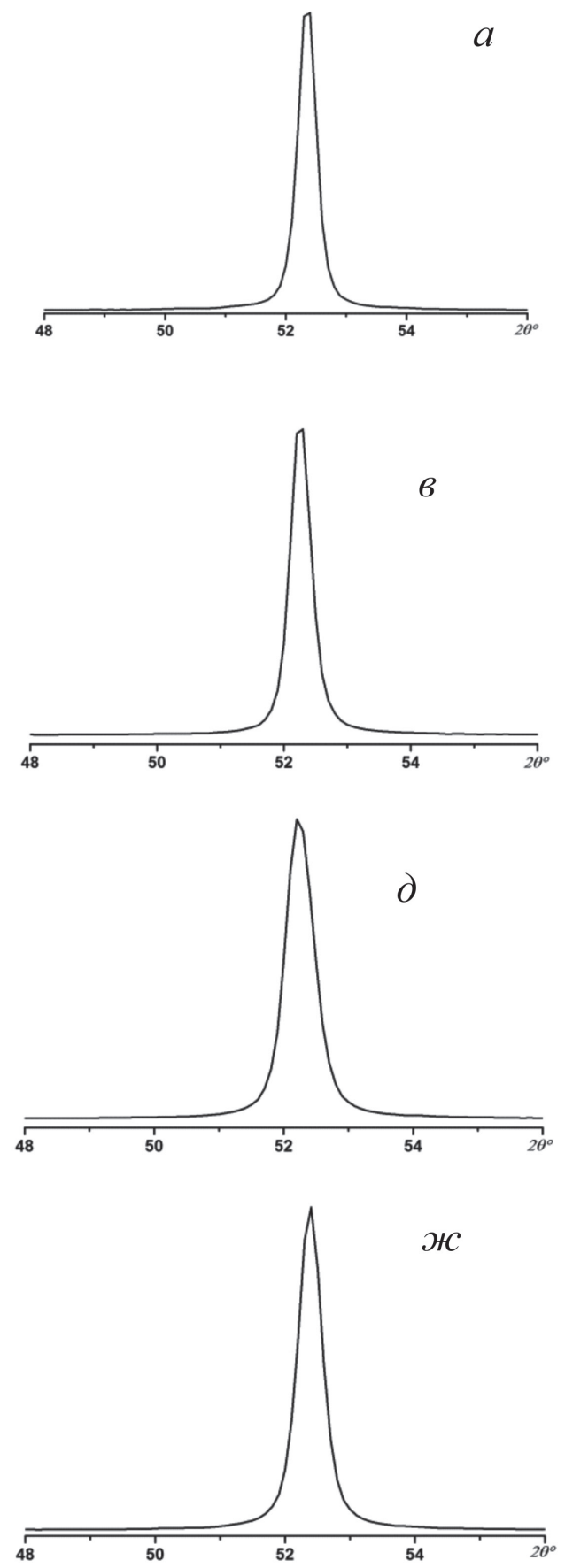

220
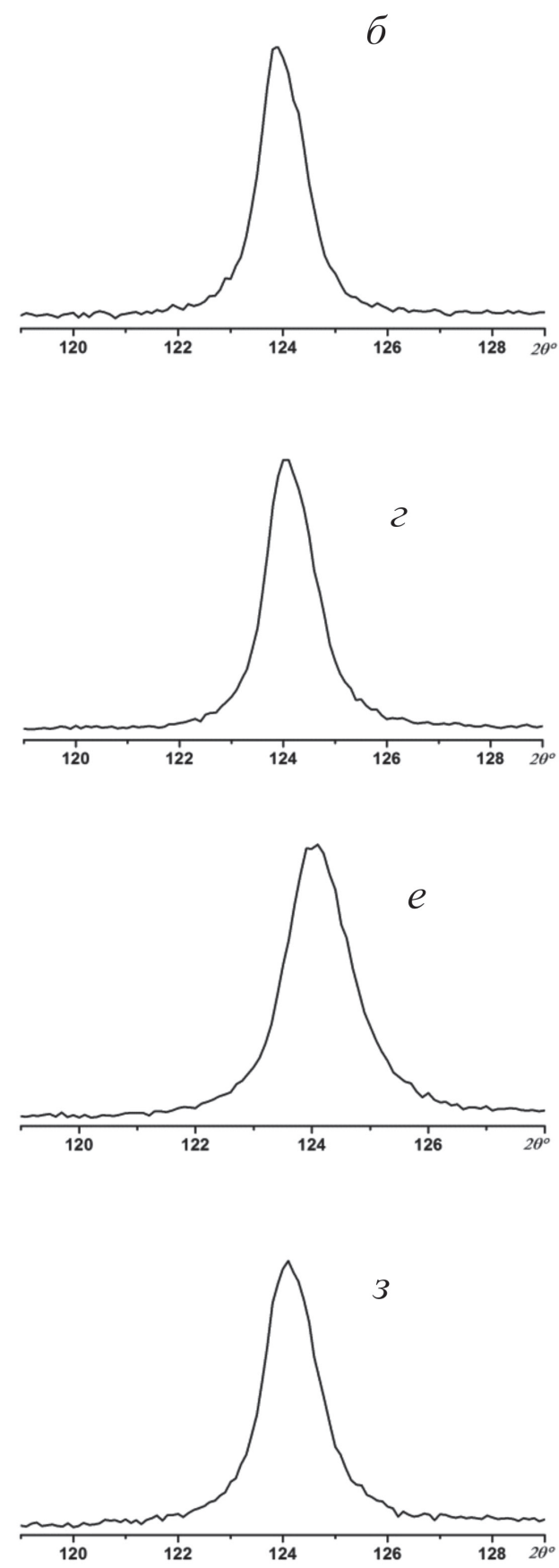

Puc. 2. Профили дифракционных линий $(110)(a, 6, \partial$, ж) и $(220)(6,2, e, 3)$ образцов из стали 45 (30-35 HRC):

$a, \sigma$ - без упрочнения; 8,2 - упрочнение МДН; $\partial, e-$ совмещенное упрочнение МДН и вращающимся постоянным магнитным полем; ж, з - совмещенное упрочнение МДН и вращающимся переменным магнитным полем

Fig. 2 - The profiles of the diffraction lines $(110)(a, 6, \partial, \varkappa)$ and $(220)(6,2, e, 3)$ of the samples made of 45 (30-35 HRC) steel:

$a, \sigma$ - without strengthening; $b, 2$ - strengthening by magnetic-dynamic rolling; $\partial, e$ - combined strengthening by magnetic-dynamic rolling and a rotating constant magnetic field; $ж$, 3 - combined strengthening by magnetic-dynamic rolling and a rotating alternating magnetic field 

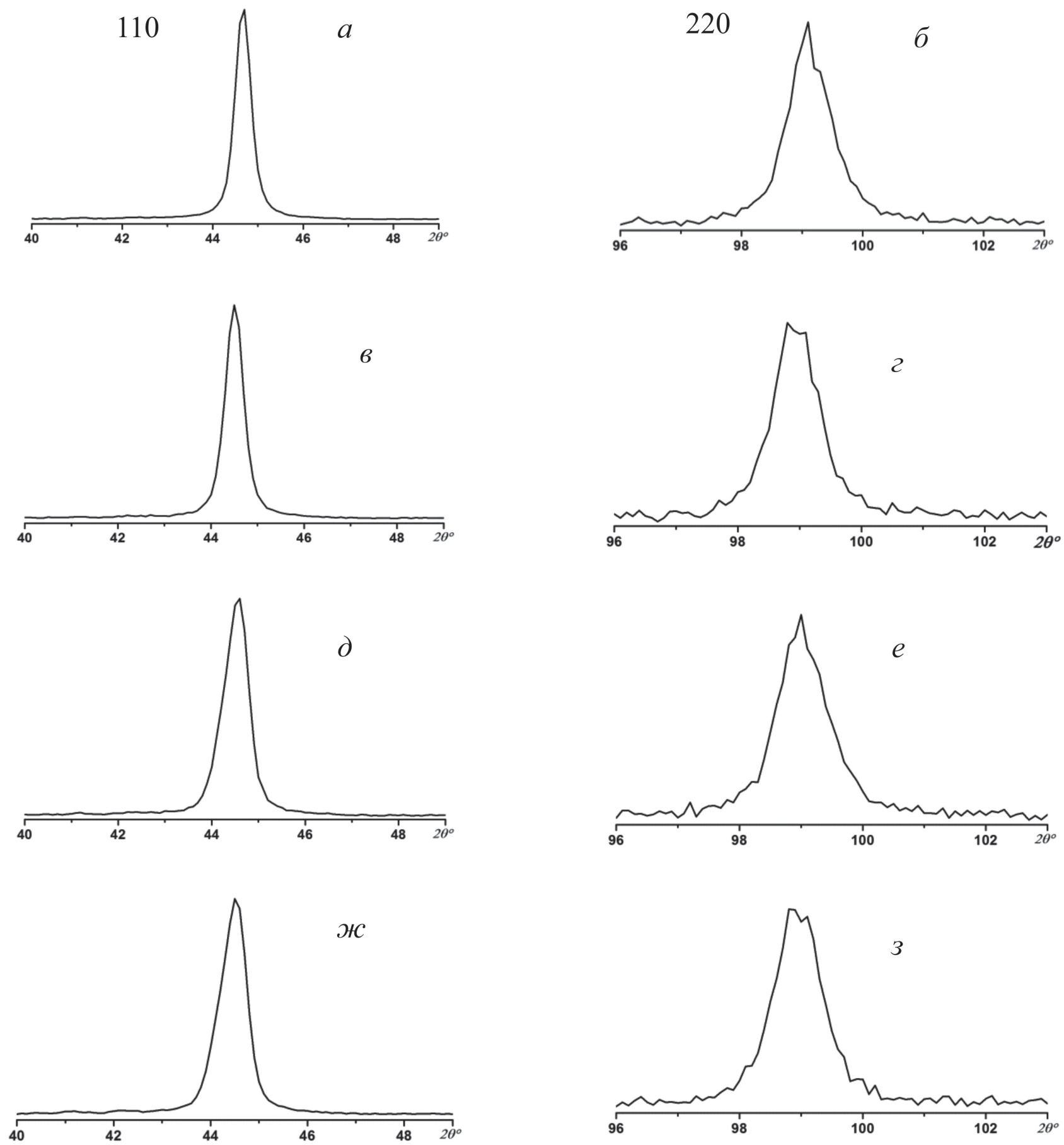

Puc. 3. Профили дифракционных линий $(110)(a, 6, \partial$, ж) и $(220)(6,2, e, 3)$ образцов из серого чугуна СЧ20:

$a$, $\sigma$ - без упрочнения; в, 2 - упрочнение МДН; $\partial, e$ - совмещенное упрочнение МДН и вращающимся постоянным магнитным полем; ж, з - совмещенное упрочнение МДН и вращающимся переменным магнитным полем

Fig. 3. The profiles of the diffraction lines (110) $(a, b, \partial, \varkappa)$ and $(220)(6,2, e, 3)$ of samples made of SCh20 grey cast iron:

$a, \sigma$ - without strengthening; 6,2 - strengthening by magnetic-dynamic rolling; $\partial, e$ - combined strengthening by magnetic-dynamic rolling and a rotating constant magnetic field; $\%$, 3 - combined strengthening by magnetic-dynamic rolling and a rotating alternating magnetic field 
Т аблиц а 1

Table 1

Значения физического уширения $\beta$ дифракционных линий (110), (220) матричной $\alpha$-фазы и размеры $D$ блоков субзеренной структуры образцов стали 45 (30-35 HRC) в исходном состоянии и после упрочнения по различным методам

The values of intrinsic broadening of the $\beta$ diffraction lines (110), (220) of the parent $\alpha$-phase and the dimensions $D$ of the blocks of the subgrain structure of the samples made of $45(30-35$ HRC) steel in the initial state and after strengthening by different methods

\begin{tabular}{|l|c|c|c|c|}
\hline \multicolumn{1}{|c|}{ Метод упрочнения } & $\beta_{110}, 10^{-3}$ рад & $\beta_{220}, 10^{-3}$ рад & $\beta_{220} / \beta_{110}$ & $D$, нм \\
\hline Без упрочнения & 4,94 & 16,49 & 3,42 & - \\
\hline МДН & 6,39 & 20,35 & 3,18 & - \\
\hline МДН + вращающееся постоянное магнитное поле & 8,31 & 20,73 & 2,49 & 25 \\
\hline МДН + вращающееся переменное магнитное поле & 6,99 & 17,77 & 2,54 & 20 \\
\hline Примечание: $\operatorname{tg} \theta_{220} / \operatorname{tg} \theta_{110}=3,84 ; \sec \theta_{220} / \sec \theta_{110}=1,91$
\end{tabular}

Таблица 2

Table 2

Значения физического уширения $\beta$ дифракционных линий (110), (220) матричной $\alpha$-фазы и размера $D$ блоков субзеренной структуры образцов из серого чугуна СЧ20 в исходном состоянии и после упрочнения по различным методам

The values of intrinsic broadening of the $\beta$ diffraction lines (110), (220) of the parent $\alpha$-phase and the dimensions $D$ of the blocks of the subgrain structure of the samples made of SCh20 grey cast iron in the initial state and after strengthening by different methods

\begin{tabular}{|l|c|c|c|c|}
\hline \multicolumn{1}{|c|}{ Метод упрочнения } & $\beta_{110}, 10^{-3}$ рад & $\beta_{220}, 10^{-3}$ рад & $\beta_{220} / \beta_{110}$ & $D$, нм \\
\hline Без упрочнения & 6,57 & 12,43 & 1,89 & - \\
\hline МДН & 8,03 & 15,79 & 1,97 & - \\
\hline МДН + вращающееся постоянное магнитное поле & 10,66 & 15,85 & 1,49 & 20 \\
\hline МДН + вращающеея переменное магнитное поле & 11,18 & 16,91 & 1,51 & 18 \\
\hline Примечание:- $\operatorname{tg} \theta_{220} / \operatorname{tg} \theta_{110}=2,85 ; \sec \theta_{220} / \sec \theta_{110}=1,54$ & & \\
\hline
\end{tabular}

Таблица 3

Table 3

Значения плотности дислокаций $\rho$, периода кристаллической решетки $a$, отношений $\Delta a / a$, межплоскостных расстояний $\Delta d / d$, напряжений $\left(\sigma_{1}+\sigma_{2}\right)$ в поверхностных слоях образцов из стали 45 (30-35 HRC) в исходном состоянии и после упрочнения по различным методам

The values of the dislocation density $\rho$, the lattice constant $a$, the ratios $\Delta a / a$, the interplanar distances $\Delta d / d$, the stresses $(\sigma 1+\sigma 2)$ in the surface layers of samples made of $45(30-35 \mathrm{HRC})$ steel in the initial state and after strengthening by different methods

\begin{tabular}{|l|c|c|c|c|c|c|}
\hline \multicolumn{1}{|c|}{ Метод упрочнения } & $a, \mathrm{Hм}$ & $\Delta a / a, \%$ & $d / n, \mathrm{Hм}$ & $\Delta d / d, 10^{-4}$ & $\rho, 10^{9} \mathrm{мм}^{-2}$ & $\left(\sigma_{1}+\sigma_{2}\right)$, МПа \\
\hline Без упрочнения & 0,28668 & - & 1,0133 & - & 4,24 & - \\
\hline МДН & 0,28687 & 0,066 & 1,0144 & 10,9 & 5,90 & -802 \\
\hline $\begin{array}{l}\text { МДН + вращающееся постоянное } \\
\text { магнитное поле }\end{array}$ & 0,28696 & 0,098 & 1,0149 & 15,8 & 7,32 & -1162 \\
\hline $\begin{array}{l}\text { МДН + вращающееся } \\
\text { переменное магнитное поле }\end{array}$ & 0,28687 & 0,066 & 1,0145 & 11,8 & 4,92 & -868 \\
\hline
\end{tabular}


Значения плотности дислокаций $\rho$, значения периода решетки $a$, отношений $\Delta a / a$, межплоскостных расстояний $\Delta d / d$, напряжений $\left(\sigma_{1}+\sigma_{2}\right)$ в поверхностных слоях образцов из серого чугуна СЧ20 в исходном состоянии и после упрочнения по различным методам

The values of the dislocation density $\rho$, the lattice constant $a$, the $\operatorname{ratios} \Delta \mathbf{a} / \mathbf{a}$, the interplanar distances $\Delta d / d$, the stresses $(\sigma 1+\sigma 2)$ in the surface layers of samples made of SCh20 grey cast iron in the initial state and after strengthening by different methods

\begin{tabular}{|l|c|c|c|c|c|c|}
\hline \multicolumn{1}{|c|}{ Метод упрочнения } & $a, \mathrm{Hм}$ & $\Delta a / a, \%$ & $d / n, \mathrm{Hм}$ & $\begin{array}{c}\Delta d / d, \\
10^{-4}\end{array}$ & $\rho, 10^{9} \mathrm{mм}^{-2}$ & $\begin{array}{c}\left(\sigma_{1}+\sigma_{2}\right), \\
\text { МПа }\end{array}$ \\
\hline Без упрочнения & 0,28651 & - & 1,0136 & - & 6,2 & - \\
\hline МДН & 0,28684 & 0,11 & 1,0145 & 8,9 & 10,0 & -655 \\
\hline $\begin{array}{l}\text { МДН + вращающееся } \\
\text { постоянное магнитное поле }\end{array}$ & 0,28689 & 0,26 & 1,0159 & 17,8 & 10,8 & -942 \\
\hline $\begin{array}{l}\text { МДН + вращающееся } \\
\text { переменное магнитное поле }\end{array}$ & 0,28715 & 0,22 & 1,0153 & 16,8 & 11,5 & -846 \\
\hline
\end{tabular}

Результаты исследований микроструктуры упрочненных заготовок из стали и серого чугуна представлены на рис. 4 и 5 и в табл. 5, 6.

Результаты рентгеноспектрального микроанализа упрочненного поверхностного слоя образцов из стали и серого чугуна представлены в табл. 7 и 8.

Анализ результатов рентгеноструктурных исследований (см. табл. 1-4) показал, что разработанный метод совмещенной упрочняющей обработки МДН и вращающимся постоянным или переменным магнитным полем позволяет сформировать в поверхностном слое заготовок наноразмерную субзеренную структуру с размером блоков (фрагментов) 20...25 нм для стали и $18 \ldots 20$ нм для серого чугуна. При этом при упрочнении МДН (когда магнитное воздействие на заготовку отсутствует) наличия в поверхностном слое заготовок наноразмерной субзеренной структуры не выявлено. Данное обстоятельство указывает на то, что только при комплексном магнитно-силовом воздействии обеспечивается наноструктурирование поверхностного слоя ферромагнитных заготовок. Причем важную роль в процессе совмещенного упрочнения играет действующее на поверхность ферромагнитной заготовки вращающееся магнитное поле.

Физическая модель получения в поверхностном слое ферромагнитных деталей наноразмерной субзеренной структуры может быть представлена следующим образом. В локальном объеме металла зерна феррита контактируют между собой и находятся в уравновешенном состоянии. В процессе совмещенного МДН колеблющиеся деформирующие шары инструмента осуществляют многократное импульсно-ударное деформирование элементарного участка ферромагнитной заготовки. Вследствие этого имеет место периодическое силовое воздействие на исходные зерна металла, вызывающее их разрушение на более мелкие части (субзерна). Затем в силу периодичности действия силы деформирования осуществляется дробление только что полученных субзерен на более мелкие фракции (блоки). Таким образом, степень дробления (измельчения) зерен упрочняемого материала определяется количеством полученных силовых импульсов со стороны деформирующих шаров инструмента. При этом разрушение зерен и субзерен на более мелкие фракции происходит в действующем извне постоянном или переменном вращающемся магнитном поле, вызывающем появление локальных вихревых токов, разогревающих неоднородности, как правило расположенные на границах контактирующих между собой зерен, субзерен или их фрагментов (блоков).

Возникающие в процессе многократного дробления зерен и субзерен частицы имеют неправильную асимметричную форму и свой магнитный момент, не совпадающий с направлением действия внешнего магнитного поля. Вследствие этого полученные в процессе дробления зерен и субзерен частицы, стремящиеся сориентироваться 


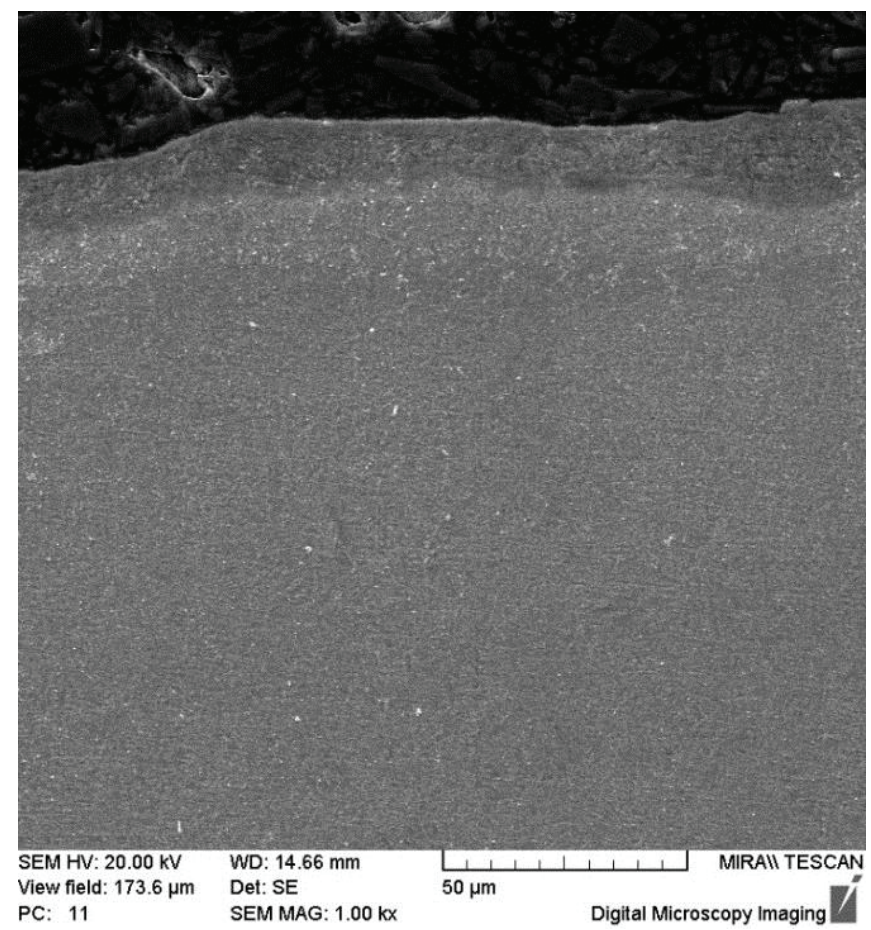

$a$

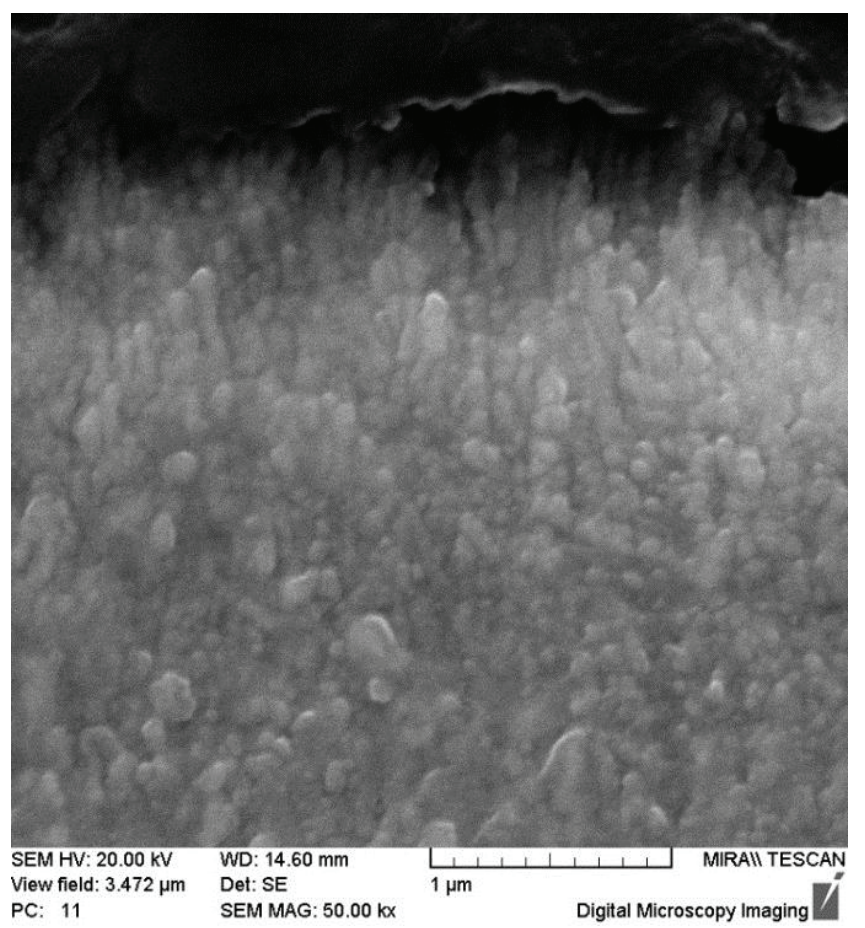

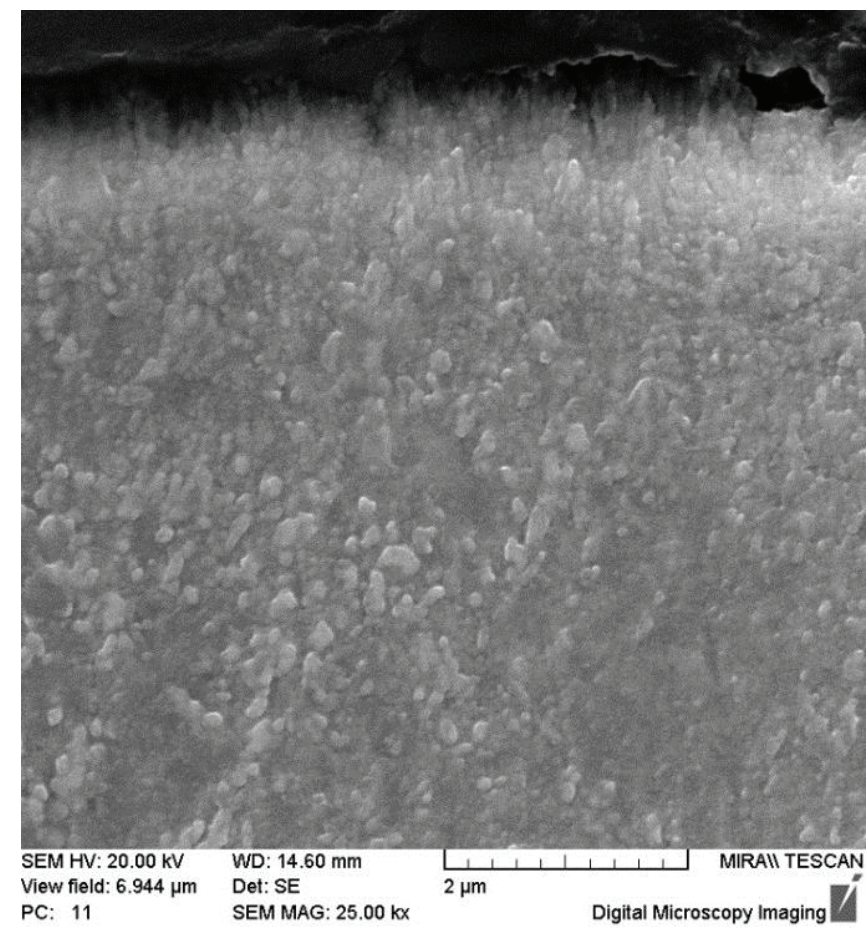

$\sigma$

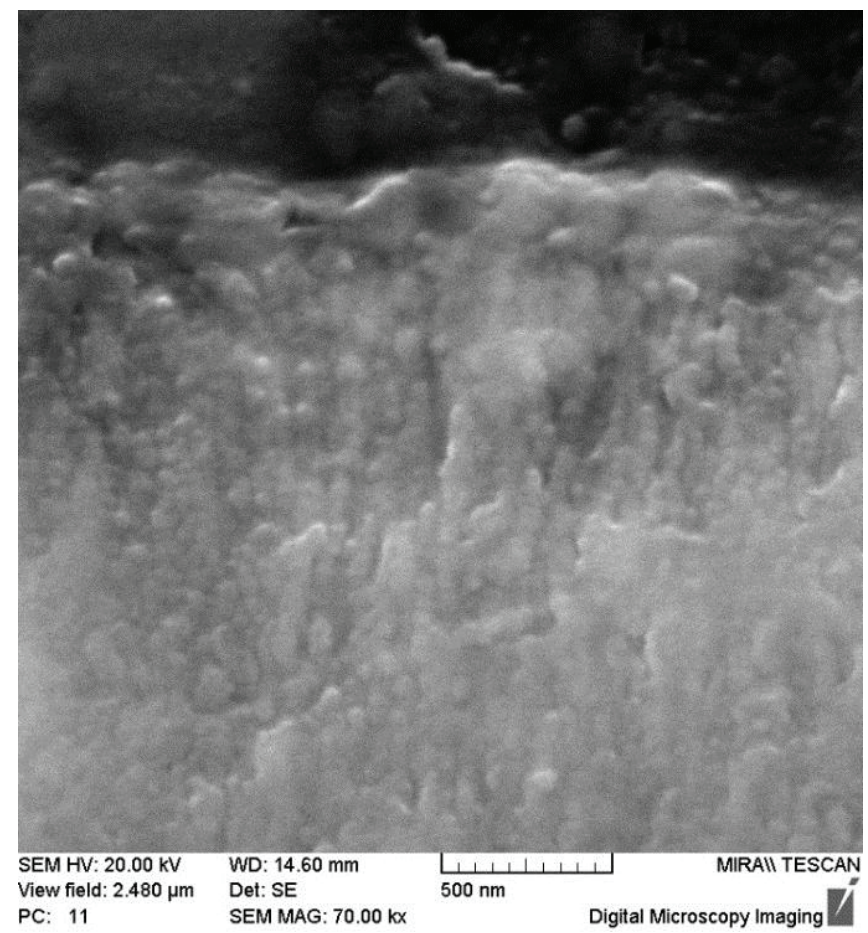

Puc. 4. Микроструктура стального образца, упрочненного совмещенной обработкой МДН и вращающимся переменным магнитным полем

Fig. 4. Microstructure of the steel sample strengthened by a combined treatment by magnetic-dynamic rolling and a rotating alternating magnetic field 

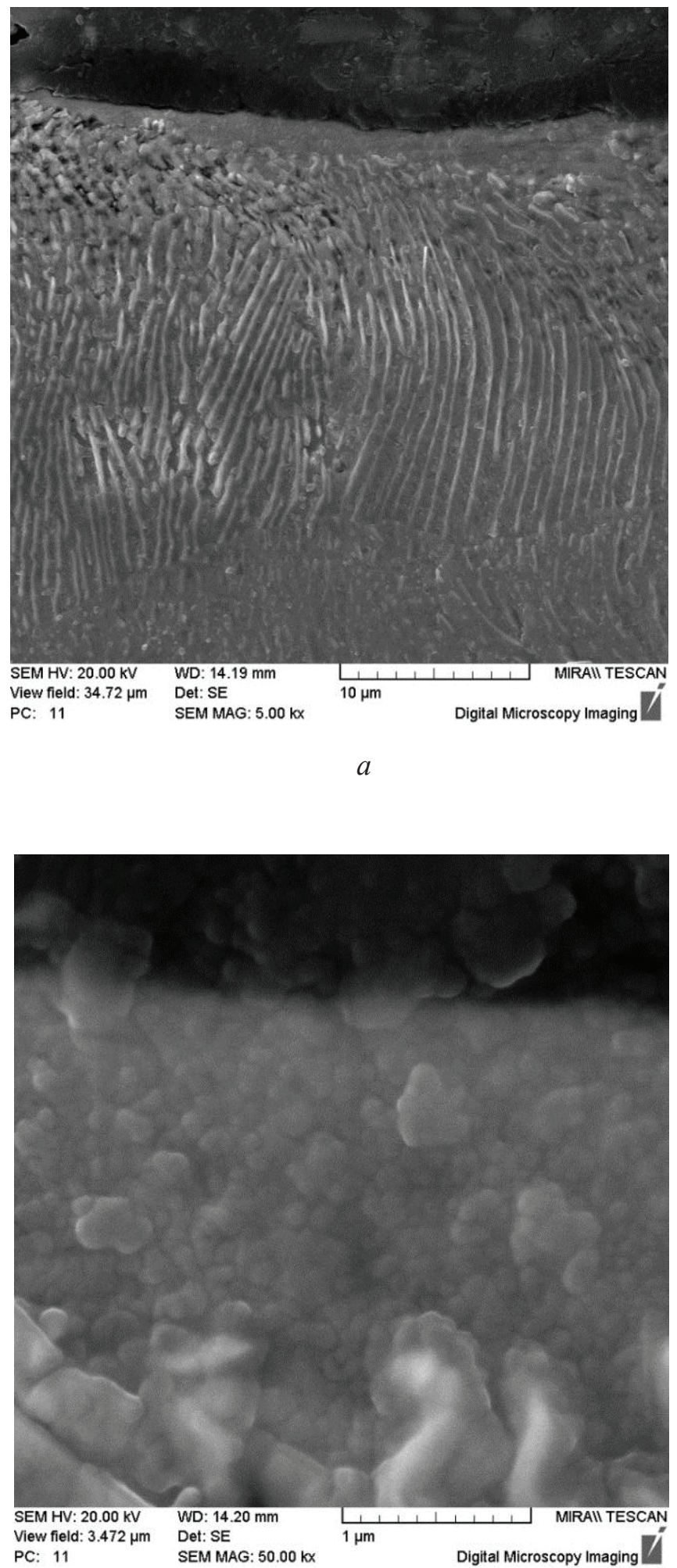

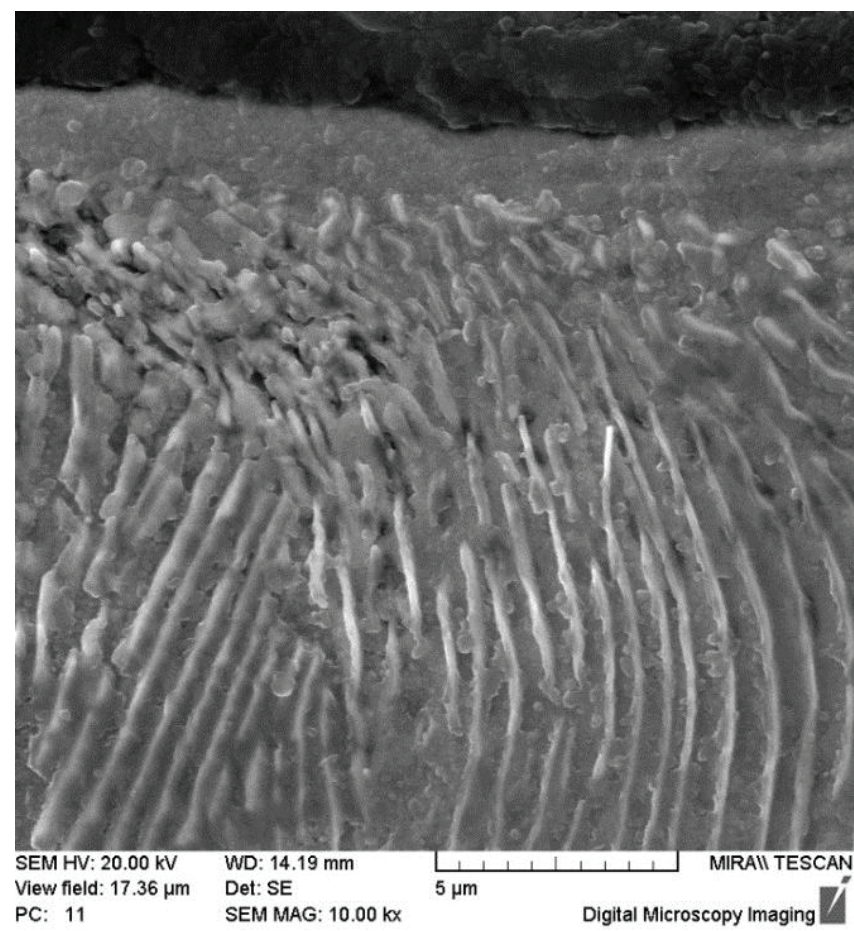

$\sigma$

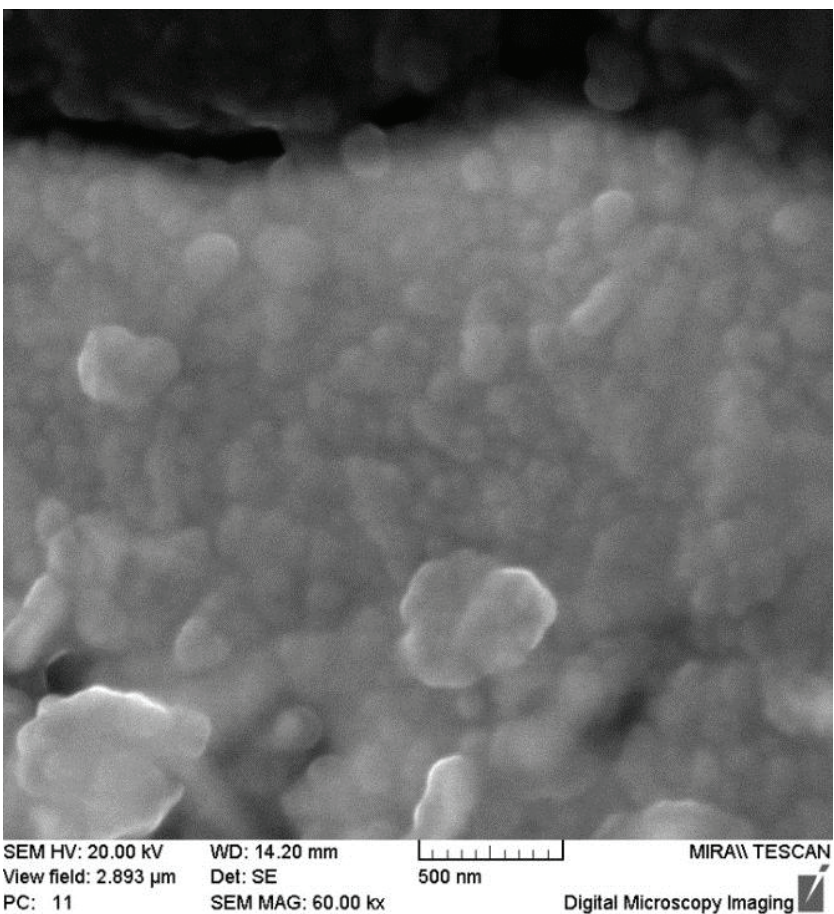

Puc. 5. Микроструктура чугунного образца, упрочненного совмещенной обработкой МДН и вращающимся постоянным магнитным полем

Fig. 5. Microstructure of the cast iron sample strengthened by a combined treatment by magnetic-dynamic rolling and a rotating constant magnetic field 
Таблица 5

Table 5

Характеристика упрочненного поверхностного слоя стальных образцов

Characteristic of the strengthened surface layer of steel samples

\begin{tabular}{|l|c|c|c|}
\hline \multicolumn{1}{|c|}{ Метод упрочнения } & $\begin{array}{c}\text { Глубина } \\
\text { измененного } \\
\text { слоя, мкм }\end{array}$ & $\begin{array}{c}\text { Глубина } \\
\text { наноструктурированного } \\
\text { слоя, мкм }\end{array}$ & $\begin{array}{c}\text { Размер субзерен } \\
\text { структурированного } \\
\text { слоя, нм }\end{array}$ \\
\hline Без упрочнения & - & - & - \\
\hline МДН & $6 \ldots 7$ & - & - \\
\hline $\begin{array}{l}\text { МДН + вращающееся постоянное } \\
\text { магнитное поле }\end{array}$ & $10 \ldots 12$ & $1,5 \ldots 2$ & $15 \ldots 100$ \\
\hline $\begin{array}{l}\text { МДН + вращающеея переменное } \\
\text { магнитнее поле }\end{array}$ & $13 \ldots 15$ & $1,8 \ldots 3$ & $25 \ldots 100$ \\
\hline
\end{tabular}

Таблица 6

Table 6

Характеристика упрочненного поверхностного слоя чугунных образцов

Characteristic of the strengthened surface layer of grey cast iron samples

\begin{tabular}{|l|c|c|c|}
\hline \multicolumn{1}{|c|}{ Метод упрочнения } & $\begin{array}{c}\text { Глубина } \\
\text { измененного } \\
\text { слоя, мкм }\end{array}$ & $\begin{array}{c}\text { Глубина } \\
\text { наноструктурированного } \\
\text { слоя, мкм }\end{array}$ & $\begin{array}{c}\text { Размер субзерен } \\
\text { структурированного } \\
\text { слоя, нм }\end{array}$ \\
\hline Без упрочнения & - & - & - \\
\hline МДН & $8 \ldots 10$ & - & $20 \ldots 100$ \\
\hline $\begin{array}{l}\text { МДН + вращающееся постоянное } \\
\text { магнитное поле }\end{array}$ & $20 \ldots 22$ & $1,8 \ldots 2,5$ & $20 \ldots 90$ \\
\hline $\begin{array}{l}\text { МДН + вращающеея переменное } \\
\text { магнитне поле }\end{array}$ & $22 \ldots 25$ & $2,5 \ldots 3,0$ & - \\
\hline
\end{tabular}

Та бл и ца 7

Table 7

Результаты рентгеноспектрального микроанализа образцов из стали 45 (30-35 HRC)

Results of X-ray spectroscopy of samples made of 45 (30-35 HRC) steel

\begin{tabular}{|l|c|c|}
\hline \multicolumn{1}{|c|}{ Метод упрочнения } & $\begin{array}{c}\text { Интенсивность линий, } \\
\text { характеризующих } \\
\text { концентрацию углерода } \\
\text { в упрочненном слое, имп/с }\end{array}$ & $\begin{array}{c}\text { Интенсивность линий, } \\
\text { характеризующих концентрацию } \\
\text { железа } \\
\text { в упрочненном слое, имп/с }\end{array}$ \\
\hline Без упрочнения & $10 \ldots 20$ & $210 \ldots 190$ \\
\hline МДН & $20 \ldots 25$ & $100 \ldots 150$ \\
\hline $\begin{array}{l}\text { МДН + вращающееся постоянное } \\
\text { магнитное поле }\end{array}$ & $35 \ldots 40$ & $100 \ldots 170$ \\
\hline $\begin{array}{l}\text { МДН + вращающеея переменное } \\
\text { магнитное поле }\end{array}$ & $20 \ldots 27$ & $120 \ldots 180$ \\
\hline
\end{tabular}


Результаты рентгеноспектрального микроанализа образцов из чугуна СЧ20

Results of X-ray spectroscopy of samples from SCh20 cast iron

\begin{tabular}{|l|c|c|}
\hline \multicolumn{1}{|c|}{ Метод упрочнения } & $\begin{array}{c}\text { Интенсивность линий, } \\
\text { характеризующих концентрацию } \\
\text { углерода }\end{array}$ & $\begin{array}{c}\text { Интенсивность линий, } \\
\text { характеризующих } \\
\text { концентрацию железа } \\
\text { в упрочненном слое, имп/с }\end{array}$ \\
\hline Без упрочнения & $10 \ldots 20$ & $90 \ldots 110$ \\
\hline МДН & $25 \ldots 35$ & $180 \ldots 200$ \\
\hline $\begin{array}{l}\text { МДН + вращающееся постоянное } \\
\text { магнитное поле }\end{array}$ & $60 \ldots 85$ & $80 \ldots 170$ \\
\hline $\begin{array}{l}\text { МДН + вращающееся переменное } \\
\text { магнитное поле }\end{array}$ & $35 \ldots 45$ & $190 \ldots 220$ \\
\hline
\end{tabular}

по направлению внешнего магнитного поля, поворачиваются в пространстве и дополнительно сглаживают разогретые локальными вихревыми токами границы в зоне их контакта с сопрягаемыми фрагментами частиц, характеризующихся накоплением несовершенств в виде дислокаций. Так как поворот частиц субзерен осуществляется многократно после каждого удара деформирующего шара, то их форма в конечном итоге становится правильной, приближающейся в сечении к окружности (см. рис. 4 и 5). Следует отметить, что при этом угол поворота частиц субзерен зависит от вида действующего магнитного поля. Так, угол поворота частиц субзерен увеличивается при действии переменного магнитного поля, предусматривающего периодическое изменение направления силовых линий на $180^{\circ}$. Увеличение угла поворота частиц субзерен под действием внешнего переменного поля обеспечивает дополнительное уменьшение их размеров, что согласуется с полученными экспериментальными данными (см. табл. 1 и 2).

Приведенные результаты исследования микроструктуры упрочненных образцов (см. табл. 5 и 6) также подтверждают гипотезу о том, что совмещенная упрочняющая обработка поверхностей ферромагнитных заготовок МДН и вращающимся постоянным или переменным магнитным полем обеспечивает формирование наноструктурированного поверхностного слоя с размером блоков субзерен от 15 до 100 нм. При этом наибольшее значение глубины упрочненного наноструктурированного поверхностного слоя (до 3 мкм) имеет место при совмещенной обработке МДН и вращающимся переменным магнитным полем, что может объясняться некоторым увеличением кинетической энергии дислокаций, перемещаемых в ферромагнитном материале вследствие возникающих магнитострикционных процессов.

Исследования микроструктуры образцов также показали, что при совмещенной обработке заготовок МДН и вращающимся магнитным полем вследствие комплексного магнитно-силового воздействия увеличивается и глубина модифицированного (измененного) поверхностного слоя. Так, по отношению к упрочнению МДН глубина модифицированного поверхностного слоя увеличилась в 1,6 и 2,7 раза, достигла 15 и 25 мкм для стальных и чугунных образцов соответственно (см. табл. 5 и 6). Это объясняется положительным влиянием процессов магнитной обработки и многократного импульсно-ударного деформирования друг на друга. Так, многократное импульсно-ударное деформирование обеспечивает резкое увеличение в элементарном объеме деформируемого металла несовершенств в виде дислокаций. Вследствие этого эффективность упрочняющего магнитного воздействия на деформированный металл, имеющий неоднородную структуру, существенно возрастает. В свою очередь, вращающееся магнитное поле способствует усилению протекания диффузионных процессов, возникающих при импульсноударном деформировании металла заготовки, что обусловливает увеличение глубины модифицированного слоя. 
Рентгеноспектральный микроанализ показал, что совмещенная упрочняющая обработка МДН и вращающимся постоянным и переменным магнитным полем приводит к увеличению концентрации углерода в наноструктурированном поверхностном слое как стальных, так и чугунных образцов (см. табл. 7 и 8). Увеличение содержания углерода в упрочненном поверхностном слое может быть обусловлено высвобождением атомов углерода вследствие дробления зерен и субзерен под комплексным магнитно-силовым воздействием и их диффундированием из нижних слоев на поверхность детали.

Установлено, что совмещенная упрочняющая обработка МДН и вращающимся переменным магнитным полем является наиболее предпочтительной, так как обеспечивает увеличение глубины модифицированного поверхностного слоя ферромагнитных деталей (см. табл. 5 и 6).

Результаты выполненных экспериментальных исследований подтверждают эффективность разработанного метода совмещенного МДН, позволяющего осуществить наноструктурирование поверхностного слоя ферромагнитных деталей машин с целью повышения их эксплуатационных свойств. В связи с этим метод совмещенного МДН рекомендуется для внедрения на предприятиях машиностроения, заинтересованных в повышении долговечности выпускаемых изделий.

В дальнейшем целесообразно проведение триботехнических испытаний поверхностей деталей пар трения упрочненных совмещеным МДН, которые позволят определить количественные показатели повышения их эксплуатационных свойств.

\section{Выводы}

1. Разработан инновационный метод совмещенного МДН, при котором на поверхность ферромагнитных деталей одновременно воздействуют концентрированным потоком энергии вращающегося постоянного (или переменного) магнитного поля с индукцией $0,10 \ldots 1,20$ Тл и колеблющимися деформирующими шарами, осуществляющими многократное импульсноударное деформирование.

2. Установлено, что совмещенная упрочняющая обработка поверхностей ферромагнитных деталей концентрированным потоком энергии вращающегося магнитного поля и многократным импульсно-ударным деформированием обеспечивает:

- формирование в поверхностном слое стальных и чугунных заготовок наноразмерной субзеренной структуры на глубину до 3,0 мкм с размером блоков от 20 до $100 \mathrm{Hм}$;

- увеличение глубины модифицированного (измененного) поверхностного слоя упрочненных образцов (по отношению к упрочнению МДН) в 1,6...2,7 ра3;

- повышение плотности дислокаций, увеличение периода кристаллической решетки обрабатываемых материалов, формирование в упрочненном поверхностном слое образцов остаточных напряжений сжатия.

\section{Список литературы}

1. Смелянский B.M. Механика упрочнения деталей поверхностным пластическим деформированием. - М.: Машиностроение, 2002. - 300 с.

2. Рыжсов Э.В. Технологические методы повышения износостойкости деталей машин. - Киев: Наукова думка, 1984. - 272 с.

3. Наукоемкие технологии в машиностроении/ под ред. А.Г. Суслова. - М.: Машиностроение, 2012. $-528 \mathrm{c}$.

4. Поляк М.С. Технология упрочнения. В 2 т. Т. 1. - М.: Машиностроение, 1995. - 832 с.

5. Поляк М.С. Технология упрочнения. В 2 т. Т. 2. - М.: Машиностроение, 1995. - 688 с.

6. Малыгин Б.В. Магнитное упрочнение инструмента и деталей машин. - М.: Машиностроение, 1989. - $112 \mathrm{c}$.

7. Белый И.В., Фертик С.М., Хименко Л.Т. Справочник по магнитоимпульсной обработке металлов. - Харьков : Вища школа, 1977. - 320 с.

8. Falaleev A.P., Meshkov V.V., Shymchenko A. Hyperplasticity effect under magnetic pulse straightening of dual phase steel // IOP Conference Series: Materials Science and Engineering. - 2016. - Vol. 153, N 1. - P. 10.

9. Kleiner M., Beerwald C., Homberg W. Analysis of process parameters and forming mechanisms within the electromagnetic forming process // CIRP Annals Manufacturing Technology. - 2005. - Vol. 24, iss. 1. P. 225-228.

10. Таранов А.C. Упрочнение валов методом ППД в ПМП // Тракторы и сельхозмашины. - 2009. № 2. - C. 44-45.

11. Aifantis E.C. The physics of plastic deformation // International Journal of Plasticity. - 1987. Vol. 3. - P. 211-247. 
12. Chen H., Kysar J.W., Yao Y.L. Characterization of plastic deformation induced by microscale laser shock peening // Journal of Applied Mechanics. - 2004. Vol. 71, iss. 5. - P. 713-723.

13. Zhang W.X., Wang T.J., Chen X. Effect of surface/ interface stress on the plastic deformation of nanoporous materials and nanocomposites // International Journal of Plasticity. - 2010. - Vol. 26, iss. 7. - P. 957-975.

14. Effect of severe plastic deformation on the properties and structural developments of high purity $\mathrm{Al}$ and Al-Cu-Mg-Zr aluminium alloy / T. Kvačkaj, J. Bidulská, R. Kočiško, R. Bidulský // Aluminium Alloys: Theory and Applications. - Rijeka, Croatia, 2011. - Ch. 1. P. $1-26$.

15. Suwas S., Bhowmik A., Biswas S. Ultra-fine grain materials by severe plastic deformation: application to steels // Microstructure and Texture in Steels and Other Materials. - London; New York: Springer, 2009. Ch. 19. - P. 325-344.

16. Технология и инструменты для отделочноупрочняющей обработки деталей поверхностным пластическим деформированием. В 2 т. Т. 1: справочник / под общ. ред. А.Г. Суслова. - М.: Машиностроение, 2014. -480 c.

17. Технология и инструменты для отделочноупрочняющей обработки деталей поверхностным пластическим деформированием. В 2 т. Т. 2: справочник / под общ. ред. А.Г. Суслова. - М.: Машиностроение, 2014. - 444 c.

18. Минаков А.П., Бунос А.А. Технологические основы пневмовибродинамической обработки нежест- ких деталей / под ред. П.И. Ящерицына. - Минск: Навука і тэхніка, 1995. - 304 с.

19. Патент 2068770 Российская Федерация. Способ поверхностного пластического деформирования и инструмент для его осуществления / А.М. Довгалев. - Опубл. 10.11.1996.

20. Патент 2089373 Российская Федерация. Способ поверхностного пластического деформирования и инструмент для его осуществления / А.М. Довгалев. - Опубл. 10.09.1997.

21. Довгалев А.M. Совмещенная отделочноупрочняющая обработка деталей машин вибродинамическим накатыванием и вращающимся магнитным полем // Вестник Белорусско-Российского университета. - 2016. - № 4. - С. 15-23.

22. Довгалев А.М. Магнитно-динамическое и совмещенное накатывание поверхностей нежестких деталей. - Могилев: Белорус.-Рос. ун-т, 2017. - 266 с.

23. Лысак Л.И. Определение истинной ширины рентгеновских интерференционных линий с применением стандартного образца // Вопросы физики металлов и металловедения: сборник трудов. - Киев: АН УССР, 1955. - № 6. - С. 40-53.

24. Кристаллография, рентгенография и электронная микроскопия / Я.С. Уманский, Ю.А. Скаков, А.Н. Иванов, Л.Н. Расторгуев. - М.: Металлургия, 1982. $-632 \mathrm{c}$.

25. Кривоглаз М.А. Дифракция рентгеновских лучей и нейтронов в идеальных кристаллах. - Киев: Наукова думка, 1983. - 115 с.

\section{Конфликт интересов}

Автор заявляет об отсутствии конфликта интересов.

(C) 2018 Авторы. Издательство Новосибирского государственного технического университета. Эта статья доступна по лицензии Creative Commons «Attribution» («Атрибуция») 4.0 Всемирная (https://creativecommons.org/licenses/by/4.0/) 


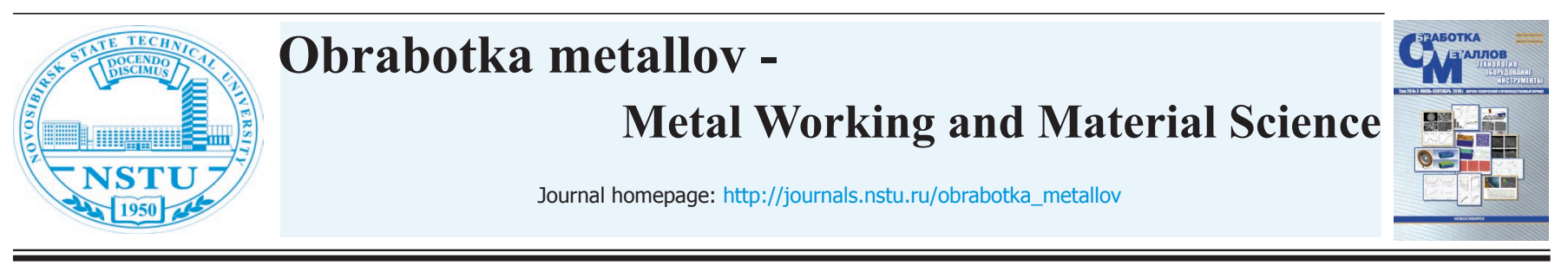

\title{
Improvement of Efficiency of Ferromagnetic Surface Strengthening by Combined Magnetic-Dynamic Rolling
}

\author{
Alexander Dovgalev*
}

Belarusian-Russian University, 43 Mira Ave., Mogilev, 212030, Republic of Belarus

(1) https://orcid.org/0000-0001-5946-5134, @ rct@bru.by

\section{ARTICLE INFO}

Article history:

Received: 15 December 2017

Revised: 10 January 2018

Accepted: 21 June 2018

Available online: 15 September 2018

\section{Keywords:}

Magnetodynamic rolling

Surface plastic deformation

Magnetic system

Combined treatment

Deforming balls

Pulse-impact deformation

Magnetic field

\section{ABSTRACT}

Introduction. The performance characteristics of the surfaces of technical system parts are provided at the finishing operations of the manufacturing process by surface strengthening methods. Despite the fact that there are a sufficiently large number of surface strengthening methods, most of it have limited manufacturing application and require specific and expensive equipment for its implementation, others have not been put into practice on a large scale or have exhausted its technological potential. In this regard, the development of innovative methods of finishing and strengthening treatment of machine part surfaces is an issue of immediate relevance. The aim of the research is to increase the efficiency of strengthening based on the complex energy deposition in the surface layer of ferromagnetic parts by a rotating magnetic field and dynamic surface plastic deformation. The research hypothesis is as follows: the combined magnetic force has an effect on a ferromagnetic part surface, helps to refine the grains of the deformed metal to a nanoscale dimension and increases the depth of the modified (altered) surface layer. Methods and approaches. The paper presents a method of finishing and strengthening treatment, in which a concentrated energy flux of a rotating magnetic field and oscillating deforming balls, which perform multiple pulse-impact deformation, act simultaneously on the surface of a ferromagnetic part. In this case, the induction of the rotating magnetic field acting on the surface of the part is selected in the range from 0.10 to $1.20 \mathrm{~T}$. In order to implement the method of finishing and strengthening treatment, a combined tool has been developed, which contains the following parts: a body; deforming balls freely installed in the annular chamber; magnetic system based on cylindrical permanent magnets made from rare-earth materials. The magnetic system of the tool is designed to create rotating magnetic field acting on the surface of the ferromagnetic part and transmit working oscillating motions to the deforming balls. The paper deals with characteristics of dislocation structures formed in the surface layer of steel and cast iron workpieces after strengthening by magnetic-dynamic rolling (MDR), combined treatment by MDR and a rotating constant magnetic field, combined treatment by MDR and a rotating alternating magnetic field. The research methods are as follows: X-ray diffraction studies of the surface layer; microstructural examination; X-ray microanalysis of the surface layer of strengthened workpieces made of steel and cast iron. Results and discussion. Analysis of the research findings allows establishing that a combined strengthening treatment by MDR and a rotating magnetic field makes it possible to form subgrain structure with nanoscale dimensions in the surface layer of steel and cast iron workpieces to a depth of up to $3.0 \mu \mathrm{m}$ with a block size of up to $100 \mathrm{~nm}$. In this case, there is an increase in the depth of the modified surface layer, in the dislocation density and in the lattice constant of the ferromagnetic materials being treated. Besides, compressive residual stresses in the strengthened surface layer of the samples are formed. It follows from the physical model of obtaining subgrain structure with nanoscale dimensions in the surface layer of ferromagnetic parts, which is presented in this paper, that the degree of grain crushing (grinding) of the material being strengthened is determined by the number of received force pulses from the deforming balls of the tool. The particles formed as a result of multiple crushing of grains and subgrains have an irregular asymmetric shape and a magnetic moment that does not coincide with the direction of the external magnetic field. As a consequence, the particles formed due to grain and subgrain crushing, trying to orient in the direction of the external magnetic field, turn in space and additionally smooth out the boundaries heated by local eddy currents in the area of their contact with the adjacent fragments of particles, characterized by accumulation of imperfections in the form of dislocations. The developed method of combined MDR belongs to nanotechnologies of surface modification and is recommended for implementation at machine building enterprises to improve operational properties of technical system parts. 
For citation: Dovgalev A.M. Improvement of efficiency of ferromagnetic surface strengthening by combined magnetic-dynamic rolling. Obrabotka metallov (tekhnologiya, oborudovanie, instrumenty) = Metal Working and Material Science, 2018, vol. 20, no. 3, pp. 18-35. doi: 10.17212/1994-6309-2018-20.3-18-35. (In Russian).

\footnotetext{
* Corresponding author

Dovgalev Alexander M., Ph.D. (Engineering), Associate Professor

Belarusian-Russian University,

43 Mira Ave.,

212030, Mogilev, Republic of Belarus

Tel.: +375222 2536 03, e-mail: rct@bru.by
}

\section{References}

1. Smelyanskii V.M. Mekhanika uprochneniya detalei poverkhnostnym plasticheskim deformirovaniem [Mechanics of parts strengthening by surface plastic deformation]. Moscow, Mashinostroenie Publ., 2002. 300 p.

2. Ryzhov E.V. Tekhnologicheskie metody povysheniya iznosostoikosti detalei mashin [Technological methods of improving wear resistance of machine parts]. Kiev, Naukova dumka Publ., 1984. 272 p.

3. Suslov A.G., ed. Naukoemkie tekhnologii v mashinostroenii [High technologies in mechanical engineering]. Moscow, Mashinostroenie Publ., 2012. 528 p.

4. Polyak M.S. Tekhnologiya uprochneniya. V 2 t. T. 1 [Strengthening technology. In 2 vol. Vol. 1]. Moscow, Mashinostroenie Publ., 1995. 832 p.

5. Polyak M.S. Tekhnologiya uprochneniya. V 2 t. T. 2 [Strengthening technology. In 2 vol. Vol. 2]. Moscow, Mashinostroenie Publ., 1995. 688 p.

6. Malygin B.V. Magnitnoe uprochnenie instrumenta i detalei mashin [Magnetic Strengthening of tools and machine parts]. Moscow, Mashinostroenie Publ., 1989. 112 p.

7. Belyi I.V., Fertik S.M., Khimenko L.T. Spravochnik po magnitoimpul'snoi obrabotke metallov [Handbook on magneto-impulse treatment of metals]. Khar'kov, Vishcha shkola Publ., 1977. 320 p.

8. Falaleev A.P., Meshkov V.V., Shymchenko A. Hyperplasticity effect under magnetic pulse straightening of dual phase steel. IOP Conference Series: Materials Science and Engineering, 2016, vol. 153, no. 1, p. 10.

9. Kleiner M., Beerwald C., Homberg W. Analysis of process parameters and forming mechanisms within the electromagnetic forming process. CIRP Annals. Manufacturing Technology, 2005, vol. 24, iss. 1, pp. 225-228.

10. Taranov A.S. Uprochnenie valov metodom PPD v PMP [Strengthening shafts by means of surface plastic forming in the variable magnet field]. Traktory $i$ sel'khozmashiny, 2009, No. 2, pp. 44-45 (in Russ.).

11. Aifantis E.C. The physics of plastic deformation. International Journal of Plasticity, 1987, vol. 3, pp. 211-247.

12. Chen H., Kysar J.W., Yao Y.L. Characterization of plastic deformation induced by microscale laser shock peening. Journal of Applied Mechanics, 2004, vol. 71, iss. 5, pp. 713-723.

13. Zhang W.X., Wang T.J., Chen X. Effect of surface/interface stress on the plastic deformation of nanoporous materials and nanocomposites. International Journal of Plasticity, 2010, vol. 26, iss. 7, pp. 957-975.

14. Kvačkaj T., Bidulská J., Kočiško R., Bidulský R. Effect of severe plastic deformation on the properties and structural developments of high purity $\mathrm{Al}$ and $\mathrm{Al}-\mathrm{Cu}-\mathrm{Mg}-\mathrm{Zr}$ aluminium alloy. Aluminium Alloys: Theory and Applications. Rijeka, Croatia, 2011, ch. 1, pp. 1-26.

15. Suwas S., Bhowmik A., Biswas S. Ultra-fine grain materials by severe plastic deformation: application to steels. Microstructure and Texture in Steels and Other Materials. London, New York, Springer, 2009, ch. 19, pp. 325-344.

16. Suslov A.G., ed. Tekhnologiya i instrumenty dlya otdelochno-uprochnyayushchei obrabotki detalei poverkhnostnym plasticheskim deformirovaniem. V 2 t. T. 1: spravochnik [Technology and tools for finishing and strengthening treatment of parts by surface plastic deformation. In 2 vol. Vol. 1: reference book]. Moscow, Mashinostroenie Publ., 2014. 480 p.

17. Suslov A.G., ed. Tekhnologiya i instrumenty dlya otdelochno-uprochnyayushchei obrabotki detalei poverkhnostnym plasticheskim deformirovaniem. V 2 t. T. 2: spravochnik [Technology and tools for finishing and strengthening treatment of parts by surface plastic deformation. In 2 vol. Vol. 2: reference book]. Moscow, Mashinostroenie Publ., 2014. 444 p.

18. Minakov A.P., Bunos A.A. Tekhnologicheskie osnovy pnevmovibrodinamicheskoi obrabotki nezhestkikh detalei [Technological fundamentals of pneumo-vibro-dynamic treatment of nonrigid parts]. Ed. by P.I. Yashcheritsyn. Minsk, Navuka i tekhnika Publ., 1995. 304 p. 
19. Dovgalev A.M. Sposob poverkhnostnogo plasticheskogo deformirovaniya i instrument dlya ego osushchestvleniya [The method of surface plastic deformation and the tool for its implementation]. Patent RF, no. $2068770,1996$.

20. Dovgalev A.M. Sposob poverkhnostnogo plasticheskogo deformirovaniya i instrument dlya ego osushchestvleniya [The method of surface plastic deformation and the tool for its implementation]. Patent RF, no. 2089373, 1997.

21. Dovgalev A.M. Sovmeshchennaya otdelochno-uprochnyayushchaya obrabotka detalei mashin vibrodinamicheskim nakatyvaniemi vrashchayushchimsya magnitnym polem [Combined finishing-and-strengthening treatment of machine parts by vibrodynamic roll forming and a rotating magnetic field]. Vestnik BelorusskoRossiiskogo universiteta $=$ Vestnik of Belarussian-Russian University, 2016, no. 4, pp. 15-23. (In Russian).

22. Dovgalev A.M. Magnitno-dinamicheskoe i sovmeshchennoe nakatyvanie poverkhnostei nezhestkikh detalei [Magnetodynamic and combined rolling of surfaces of nonrigid parts]. Mogilev, Belarussian-Russian University Publ., 2017. 266 p.

23. Lysak L.I. Opredelenie istinnoi shiriny rentgenovskikh interferentsionnykh linii s primeneniem standartnogo obraztsa [Determination of the true width of X-ray interference lines using a standard sample]. Voprosy fiziki metallov $i$ metallovedeniya; sbornik trudov AN UkrSSR [Proceedings of the Academy of Sciences of the Ukrainian SSR "Problems in the physics of metals and metallography"]. Kiev, 1955, no. 6, pp. 40-53. (In Russian).

24. Umanskii Ya.S., Skakov Yu.A., Ivanov A.N., Rastorguev L.N. Kristallografiya, rentgenografiya i elektronnaya mikroskopiya [Crystallography, X-ray diffraction and electron microscopy]. Moscow, Metallurgiya Publ., 1982. $632 \mathrm{p}$.

25. Krivoglaz M.A. Difraktsiya rentgenovskikh luchei i neitronov v ideal'nykh kristallakh [Diffraction of X-Rays and neutrons in ideal crystals]. Kiev, Naukova dumka Publ., 1983. 115 p.

\section{Conflicts of Interest}

The author declare no conflict of interest.

(C) 2018 The Authors. Published by Novosibirsk State Technical University. This is an open access article under the CC BY license (http://creativecommons.org/licenses/by/4.0/). 